Article

\title{
Potential Activity of Recycled Clay Brick in Cement Stabilized Subbase
}

\author{
Chunyu Liang ${ }^{1}$, Ying Wang ${ }^{1}$, Wenzhu Song ${ }^{2}$, Guojin Tan ${ }^{1, * \mathbb{D}}$, Yanling Li ${ }^{1}$ and Youmeng Guo ${ }^{1}$ \\ 1 School of Communications, Jilin University, 5988 RenminRoad, Changchun 130000, China; \\ liangcy@jlu.edu.cn (C.L.); wang_y17@mails.jlu.edu.cn (Y.W.); yanling@jlu.edu.cn (Y.L.); \\ guoym16@mails.jlu.edu.cn (Y.G.) \\ 2 Jilin highway administration bureau, 2518 Jiefang Road, Changchun 130000, China; swz_glj@163.com \\ * Correspondence: tgj@jlu.edu.cn
}

Received: 28 September 2019; Accepted: 27 November 2019; Published: 29 November 2019

check for updates

\begin{abstract}
Construction waste is one of the products in the process of urbanization. From the perspective of economy and environmental protection, this study used crushed construction waste clay brick to replace the fine aggregate of cement stabilized macadam subbase in certain proportions, and the optimum proportion was obtained according to the unconfined compressive strength of 7 days (d), $28 \mathrm{~d}$, and $90 \mathrm{~d}$. The "modified EDTA titration experiment" was also used to explain how the potential activity of construction waste clay brick works in cement stabilized macadam. The result obtained is that an optimal replacement ratio of $50 \%$ exists when using construction waste clay brick to replace the fine aggregate of cement stabilized macadam, and its unconfined compressive strength is higher than that of the $0 \%$ replacement ratio specimens; that is, the potential activity of the construction waste clay brick contributes the most to the unconfined compressive strength of the specimens at this proportion. According to the blending method and proportion obtained in this study, the application of construction waste clay bricks in a practical project can maximize environmental protection in road engineering and economic benefits simultaneously.
\end{abstract}

Keywords: road engineering; construction waste clay brick; cement stabilized macadam; unconfined compressive strength; potential activity

\section{Introduction}

Predictions show that a large amount of sand consumption in the future will not only create economic pressure on the construction industry but also cause the erosion and degradation of the world's major ecosystems. The global construction waste crisis will get worse; global waste production will increase by $70 \%$ by 2050 in comparison to 2016, and the global waste crisis will spur innovation in waste management. Due to the boom of the construction industry, the price of sand will increase significantly [1]. However, the large amount of construction waste produced by the process of demolition and reconstruction is one of the inevitable additional products in the process of urbanization. Among the construction waste includes a large number of waste concrete blocks, waste clay bricks, waste steel bars, waste wires and cables, waste plastic products, and so on. Among them, clay bricks and concrete blocks account for about $80 \%$ of the total [2]. Marzouk and Azabbuilt a system dynamics methodology of the construction and demolition waste management sector by developing a dynamic model that is capable of studying the behavior of landfill process on both the short and long run and its impacts on the environment and economy. In Egypt, this system dynamics methodology results show that the recycling of construction and demolition waste would reduce the costs required to mitigate air pollution by $\$ 16,161.35$ billion over 20 years [3]. 
In order to reduce the environmental and economic pressure of construction waste, the reuse of it is an effective method. As for the reuse of construction waste in road engineering, it is usually used for filling roadbeds without secondary crushing, while after secondary crushing, it can be used as aggregate in asphalt pavement and as a cement stabilized base layer [4,5]. Waste concrete blocks are widely used in road engineering. The superiority of concrete materials for housing construction and considerable secondary hydration are the reasons why waste concrete blocks are widely used among several types of construction wastes. However, due to its high strength, the crushing process is complicated, the requirements for the crushing machine are higher, and the crushing process is difficult. There are also uncontrollable interference factors, such as cement that did not fully hydrate, aggregates from different sources with different strengths, and some waste bricks that cannot be completely removed [6]. In comparison, waste clay bricksare easy to be picked out and crushed and have a lower transportation burden. A stone-crushing machine can be used to crush waste clay bricks, which can save more expenditure.

In response to the management of construction waste, many developed countries began to take action to solve the problem in the 1970s and 1980s. Examples include the Solid Waste Treatment Act of 1965 in the United States and the Waste Treatment Act of 1970 in Japan [7]. Many other developed countries, such as Germany, Korea, Denmark, and Singapore also made initial efforts to solve this problem and had momentous success [8,9]. In China, regulations related to construction waste have been carried out since 1992. The Regulations on the Management of City Appearance and Environmental Hygiene have stipulated that the responsible persons for the disposal of construction waste must take timely clearance and transportation. A series of plans also have been implemented [10]. These actions above are the first step that has been taken in encouraging the recycling of construction waste and governing the unreasonable disposal of construction waste, which laid a foundation for improving the relevant laws and regulations for the recycling and reuse of construction waste.

In terms of construction waste recycling, most research studies have focused on cement concrete and asphalt concrete. Xue et al. considered that the optimum amount of construction waste composite powder in cement concrete is $30 \%$. This amount of construction waste composite powder putsthe concrete in a more compact and low-alkali condition, thus enhancing the macroscopic frost resistance [11]. Peng et al. combine silicon powder, slag powder, and recycled construction waste regenerated powder in concrete; they comprehensively study the performance test of using construction waste regenerated powders to replace silicon powder and cement in concrete, obtaining the optimal water-binder ratio range of $0.18-0.20$. The results show that the particle size of regenerated powders is mostly larger than that of silicon powder particles, and some of them are smaller than that of cement particles. Furthermore, the pozzolanic reaction of regenerated powders as active admixtures is weak, reflecting the macroscopical performance in which the resistance to chloride ion permeability and the resistance to shrinkage are enhanced with the increase of the amount of the regenerated powders, while simultaneously the unconfined compressive strength and flexural strength are weakened [12]. Cheng studied the application of fine aggregate partially replaced by fly ash and coarse aggregate partially replaced by waste brick in concrete. The results showed that when the replacement rate of both fly ash and waste brick was 30\%, the compressive strength of recycled concrete reached the highest value [13]. The physical and mechanical properties of four kinds of coarse aggregate with different particle sizes in fresh concrete and hardened concrete were also studied. The results show that harder original brick directs the stronger compressive strength of the concrete, and the higher density directs the higher concrete strength. The flexural strength of concrete produced with a crushed brick aggregate was approximately $8 \%$ less than that of concrete made with granite aggregate [14]. Kristina et al. replaced natural macadam fine aggregate with recycled brick fine aggregate of $0 \%, 25 \%$, and $50 \%$ in concrete, obtaining 25,50,75, and 100 routine freeze-thaw cycles at 28 and 60 days of curing age, respectively. Combining the subsequent compressive strength and flexural strength tests, it was concluded that the addition of recycled brick fine aggregate could improve the frost resistance and long-term strength of concrete to a certain extent [15]. Zhao et al. mix coarse and fine aggregates of 
construction waste into concrete, respectively. The hardening density, drying shrinkage coefficient, and water absorption rate were taken as reference, the optimum replacement ratio of coarse aggregate and fine aggregate is less than $25 \%$ and within the scope of $50 \%-75 \%$, respectively [16]. Hu et al. mix recycled clay brick aggregate with $20 \%, 40 \%, 60 \%, 80 \%$, and $100 \%$ of coarse aggregate and fine aggregate in cement stabilized macadam, respectively. The compressive strength, splitting strength, compressive modulus of resilience, shrinkage strain, and freeze resistance index were used as references in the study, and the maximum mixing ratio of coarse aggregate and fine aggregate obtained was $70 \%$ and $90 \%$, respectively [17]. Turanli et al. used clay bricks as pozzolanic materials after fine grinding. An ASTM accelerated mortar bar test and scanning electron microscopy (SEM) showed that fine grinding clay bricks could effectively inhibit the expansion caused by the alkali-aggregate reaction [18]. Peng replaced recycled aggregate for coarse aggregate in asphalt concrete and obtained the optimum replacement ratio of $30 \%-40 \%$ with the high-temperature performance taken as a reference; their results also showed an optimum replacement ratio range of $60 \%-70 \%$, using the residual stability and freeze-thaw splitting strength as references. When the replacement ratio of recycled aggregate is less than $60 \%$, the adverse effects on low-temperature performance and fatigue resistance are controllable [19].

It can be seen that the research of recycled construction waste clay brick aggregate (RBA) in concrete and asphalt concrete is more indepth, and some referential conclusions are also drawn in terms of the replacement ratio and pozzolanic activity. In this study, the application of clay brick in cement stabilized macadam subbase will be studied, and the influence of the potential activity of RBA using it instead of fine aggregate partly on the unconfined compressive strength of this structure layer will be discussed. To study the microscopic mechanism of the tendency of strength, we also used the physical and chemical methods to verify the practicability and feasibility of RBA application in road subbase.

\section{Material}

\subsection{Aggregate}

Crushed basalt aggregate (CBA) produced from Tumen mountain, Jilin province in China, was crushed into four grades: CBA I (20-30 mm), CBA II (10-20 mm), CBA III (5-10 mm), and CBA IV $(0-5 \mathrm{~mm})$. The four grades of CBA will be screened into a single particle size, and the cement stabilized macadam test gradation is formed by a mix proportion design. RBA is taken from the demolition of the shanty renovation building in China, Jilin Province. It is crushed into two grades: RBA I (0-20 mm) and RBA II (0-5 mm). All these grades were applied to the experiment after sieving and then dispensed experiment gradation. The sieving results are shown in Figures 1 and 2.

The experimental gradation of cement stabilized macadam was designed [20], which satisfies the gradation range stipulated in the Technology Guidelines for the Construction of Highway Roadbases (JTG/T F20-2015) and is close to the lower bound. The experimental gradation curve is shown in Figure 3. 


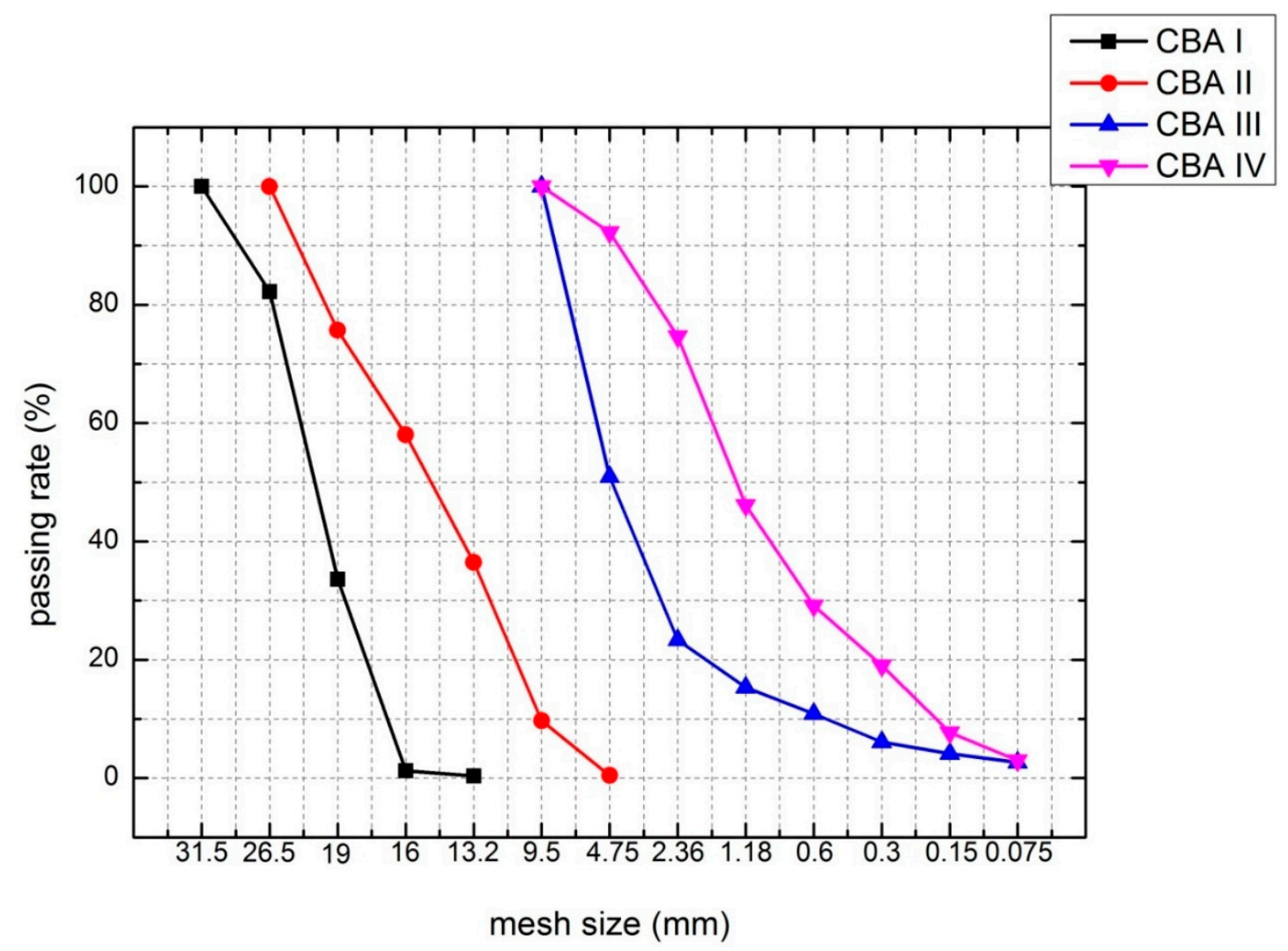

Figure 1. Grades sieving proportion.

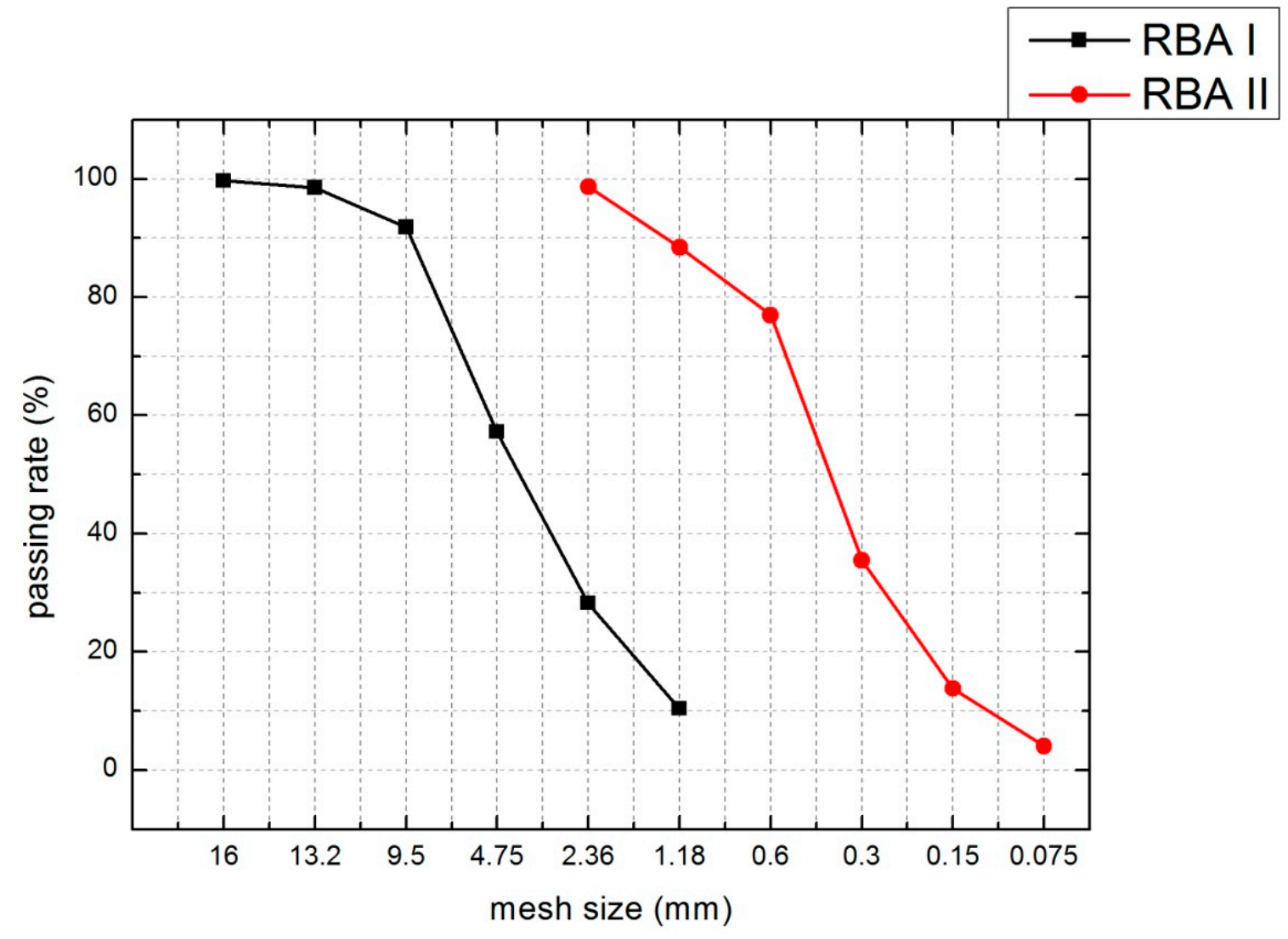

Figure 2. Grades sieving proportion. 


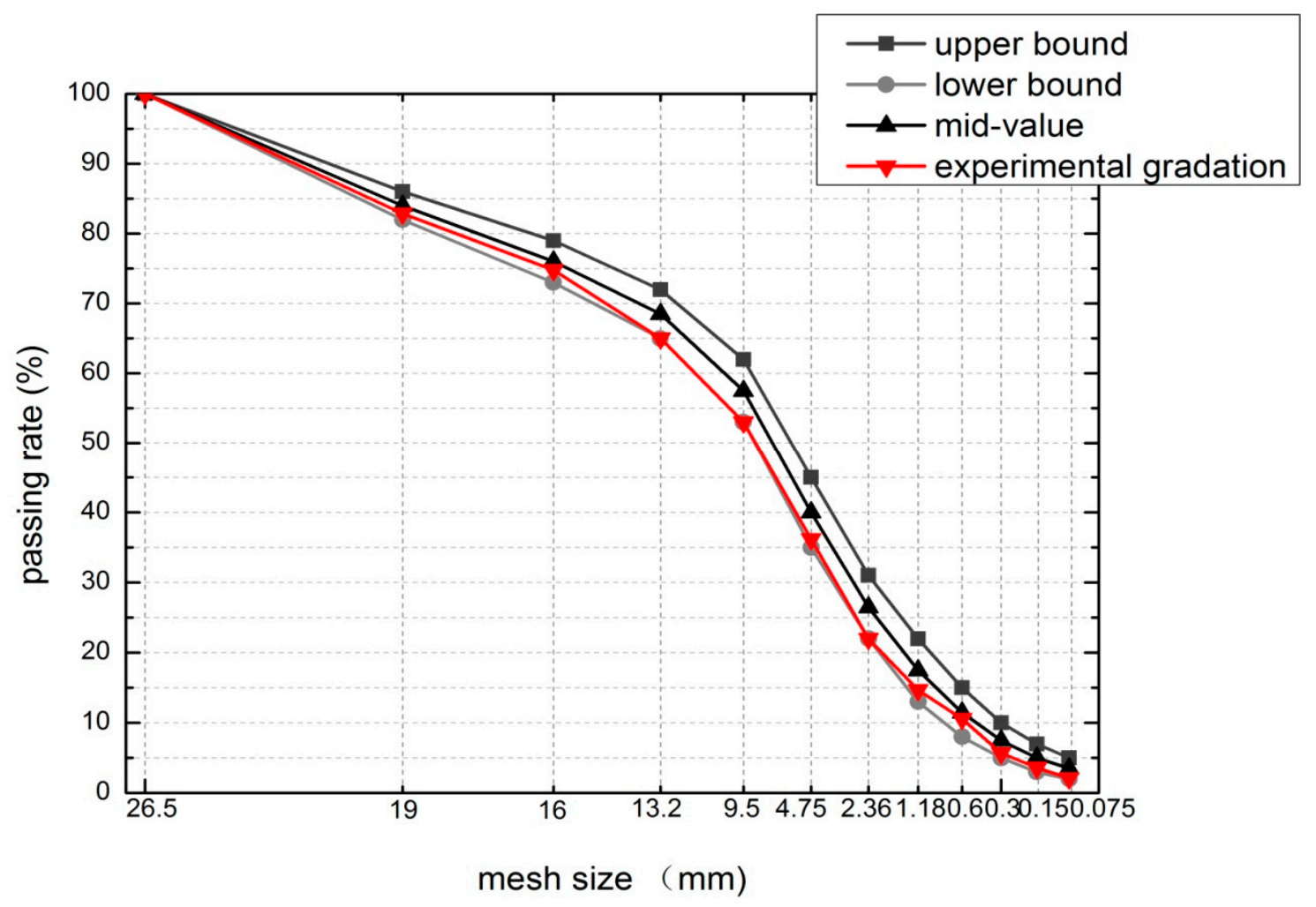

Figure 3. Gradation curve.

Several basic performance tests of aggregates, such as the crushed stone value, percentage of flat-elongated particle, water absorption, and apparent specific gravity were carried out on the basis of the Test Methods of Aggregate for Highway Engineering (JTG E42-2005). The plastic index test was carried out according to the Test Methods of Soils for Highway Engineering (JTG E40-2007). The results of the tests and the corresponding reference values in specification (JTG/T F20-2015) are shown in Table 1, and the coarse and fine aggregate were divided by a particle size of $4.75 \mathrm{~mm}$. The CBA and RBA mixtures of different proportions were tested, whose proportions will be used in the experiment.

Table 1. Aggregate basic performance.

\begin{tabular}{|c|c|c|c|c|c|c|c|}
\hline & \multicolumn{3}{|c|}{ Fine Aggregate } & \multicolumn{4}{|c|}{ Coarse Aggregate } \\
\hline & $\begin{array}{l}\text { Plastic } \\
\text { Index }\end{array}$ & $\begin{array}{c}\text { Water } \\
\text { Absorption (\%) }\end{array}$ & $\begin{array}{c}\text { Apparent } \\
\text { Specific Gravity }\end{array}$ & $\begin{array}{c}\text { Crushed Stone } \\
\text { Value (\%) }\end{array}$ & $\begin{array}{c}\text { Flat-Elongated } \\
\text { Particle (\%) }\end{array}$ & $\begin{array}{c}\text { Water } \\
\text { Absorption (\%) }\end{array}$ & $\begin{array}{c}\text { Apparent } \\
\text { Specific Gravity }\end{array}$ \\
\hline $0 \%^{\mathrm{a}}$ & 4.34 & 1.73 & 2.68 & 21.63 & 9.57 & 1.24 & 2.73 \\
\hline $40 \%$ a & 9.84 & 8.21 & 2.50 & 25.74 & 9.72 & 7.42 & 2.58 \\
\hline $50 \%^{a}$ & 13.97 & 10.32 & 2.41 & 28.45 & 9.89 & 9.98 & 2.51 \\
\hline $100 \%^{a}$ & 60.50 & 17.60 & 2.11 & 41.53 & 9.97 & 17.36 & 2.33 \\
\hline Reference value & $\leq 12$ & - & - & $\leq 30$ & - & - & - \\
\hline
\end{tabular}

${ }^{a}$ Replace proportion of recycled construction waste clay brick aggregate (RBA) in crushed basalt aggregate (CBA) specimens.

According to the data in Table 1, as the proportion of RBA increase in specimens, the indexes such as the plastic index, water absorption, and crushed stone value also increase; however, the apparent specific gravity decreases at the same time, while the flat-elongated particlesare maintainedat a steady level. When only comparing two kinds of proportion, $0 \%$ and $100 \%$, the apparent specific gravity of RBA $(100 \%)$ is generally smaller than that of CBA $(100 \%)$, and contraposing RBA, the fine aggregate is much smaller than the coarse aggregate. In terms of water absorption, RBA is 10 to14 times as much 
as CBA, which means that RBA can absorb more water than CBA under the same conditions. The crushed stone value of RBA is about twice that of CBA. This property leads to the strength of RBA being much weaker than that of CBA. The plastic index of CBA is much smaller than the reference value and less than that of RBA, which proves that the water absorption and water requirement of RBA are much larger than those of CBA, so it is not suitable to be used as aggregates alone. As an aspect of the percentage of flat-elongated particles, these two kinds of aggregates show similar test results, which prove that RBA will not produce more collapsed particles under the same crushing method.

\subsection{Composition}

Scanning electron microscopy (SEM) and quantitative energy dispersive X-ray diffraction (XRD) were used to scan the crushed powder of construction waste clay brick, and the main substances that exist in crystalline form and chemical elements were analyzed.

Construction waste clay brick powder was scanned by the above two micro detection methods; Figures 4 and 5 were obtained as scanning results. Figure 4 illustrates four points of the SEM scanning result, which showed that there are several major elements in construction waste clay brick such as $\mathrm{O}, \mathrm{Si}$, and $\mathrm{C}$, with a relatively large mass percentage of each as shown in Table 2 . Among the other elements, $\mathrm{Al}$ is the most abundant, and $\mathrm{Ca}, \mathrm{Fe}, \mathrm{Mg}$, and $\mathrm{Na}$ all exist in a small mass percentage. In these scanning pictures, 1500x magnification was used to observe the details. Figure 5 is the XRD scanning result, which shows that quartz $\left(\mathrm{SiO}_{2}\right)$, calcite $\left(\mathrm{CaCO}_{3}\right)$, chalcopyrite $\left(\mathrm{CuFeS}_{2}\right)$, kyanite $\left(\mathrm{Al}_{2} \mathrm{SiO}_{5}\right)$, and the residual graphite $(\mathrm{C})$ from the process of firing are contained as the main crystalline compositions in construction waste clay brick.

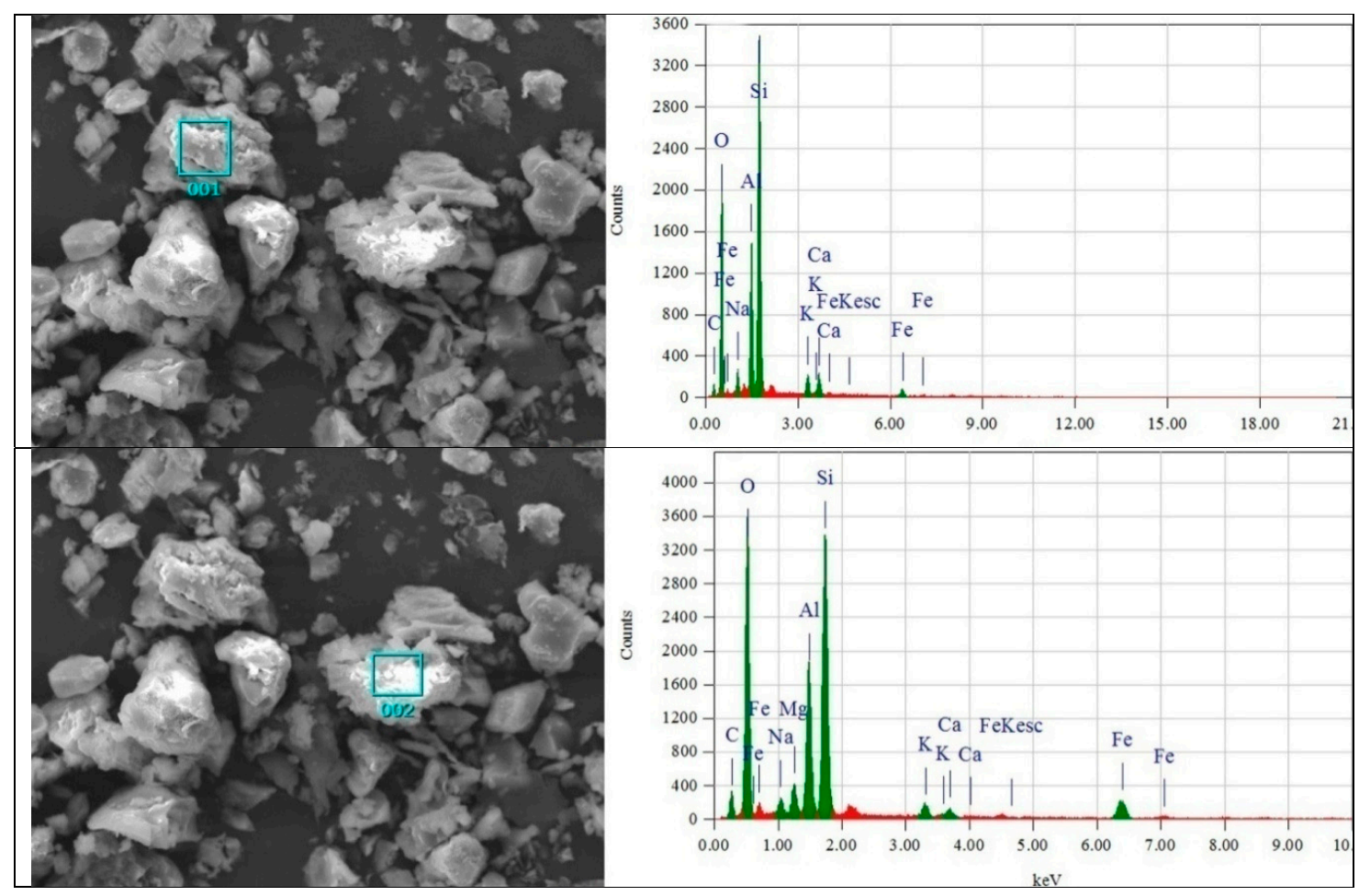

Figure 4. Cont. 


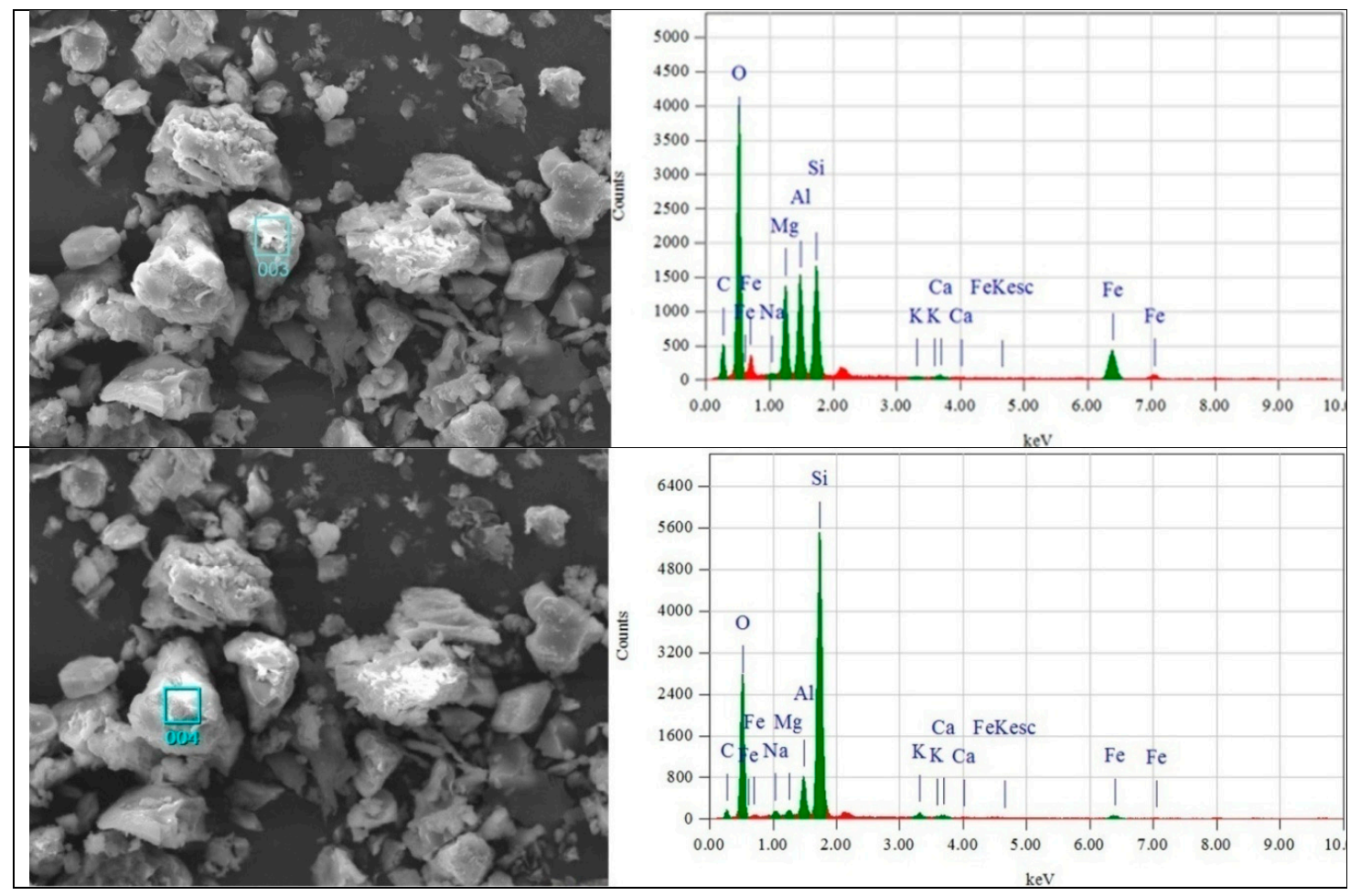

Figure 4. Waste clay brick powder SEM scanning result.

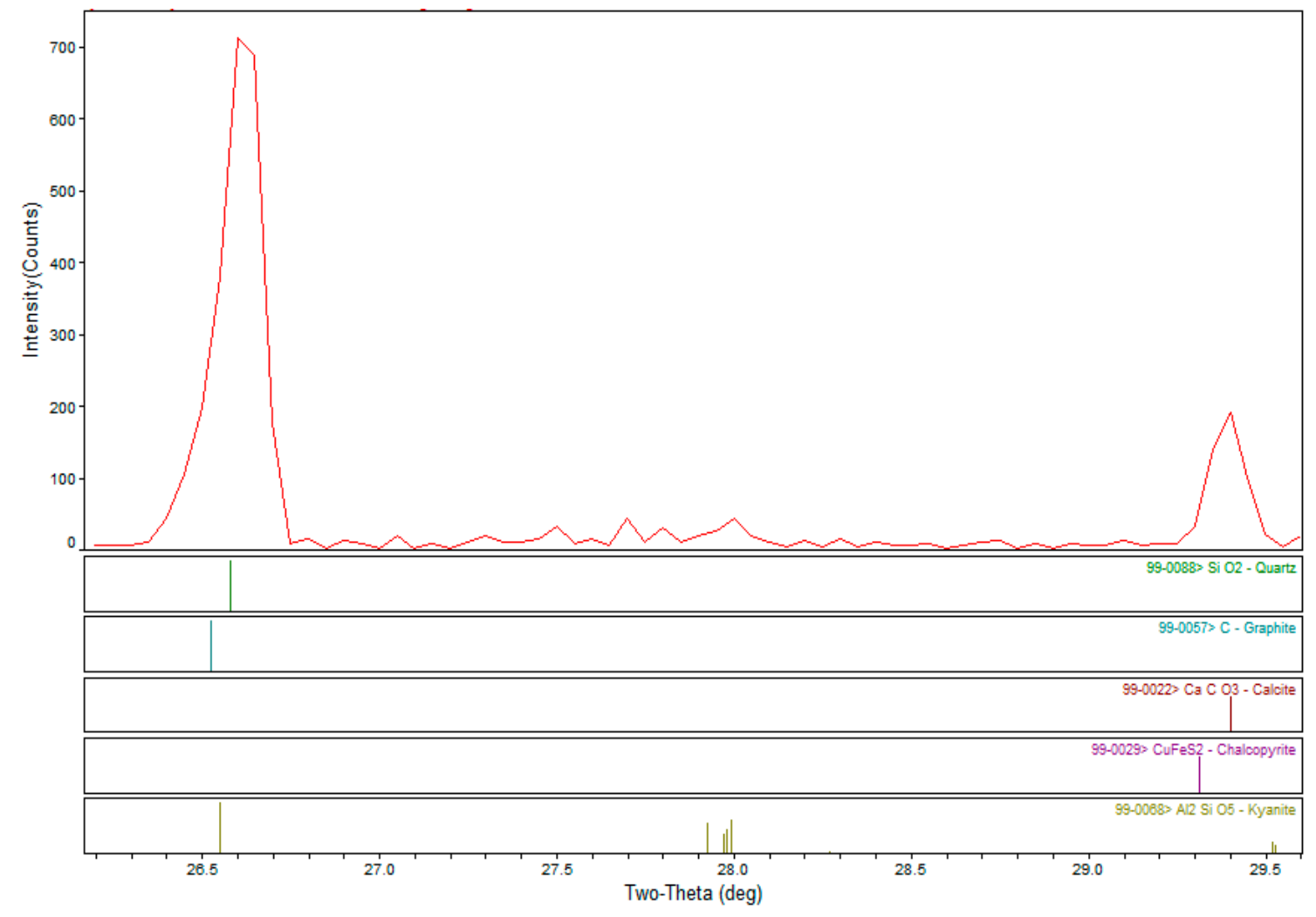

Figure 5. Construction waste clay brick powder XRD scanning. 
Table 2. Scanning mean value of element composition.

\begin{tabular}{ccccc}
\hline Element & Mass (\%) & Atom (\%) & Sigma & Energy (keV) \\
\hline C(Graphite) & 16.69 & 24.57 & 0.19 & 0.277 \\
O & 49.08 & 54.60 & 0.29 & 0.525 \\
$\mathrm{Na}$ & 1.16 & 0.91 & 0.05 & 1.041 \\
$\mathrm{Mg}$ & 2.97 & 2.11 & 0.05 & 1.253 \\
$\mathrm{Al}$ & 6.53 & 4.33 & 0.08 & 1.486 \\
$\mathrm{Si}$ & 18.75 & 12.02 & 0.13 & 1.739 \\
$\mathrm{~K}$ & 0.96 & 0.45 & 0.04 & 3.312 \\
$\mathrm{Ca}$ & 0.75 & 0.35 & 0.03 & 3.690 \\
$\mathrm{Fe}$ & 3.86 & 1.21 & 0.09 & 6.398 \\
\hline
\end{tabular}

\subsection{Cement}

The cement used in this study is P.O 42.5R Portland cement produced by Jilin Yatai Company in China, which was stored in a cool, ventilated, desiccative room. The performance indexes of cement are shown in Table 3.

Table 3. Cementperformance index.

\begin{tabular}{|c|c|c|c|c|c|c|c|}
\hline \multirow{3}{*}{ Type } & \multirow{3}{*}{ Comparison } & \multicolumn{6}{|c|}{ Physical Performances } \\
\hline & & \multirow{2}{*}{\multicolumn{2}{|c|}{ Setting Time (h) }} & \multicolumn{4}{|c|}{ Strength (MPa) } \\
\hline & & & & \multicolumn{2}{|c|}{ Flexural Strength } & \multicolumn{2}{|c|}{ Unconfined Compressive Strength } \\
\hline \multirow{2}{*}{ P.O 42.5R } & Reference Value & $\geq 0.75$ & $\leq 10$ & $\geq 4.0$ & $\geq 6.5$ & $\geq 21.0$ & $\geq 42.5$ \\
\hline & Test result & 2 & 3 & 5.2 & 8.5 & 25.0 & 53.0 \\
\hline
\end{tabular}

The reference value in Table 3 is stipulated by specification (The Methods of Cement and Concrete for Highway Engineering JTG E30-2005).

\section{Test Scheme}

To achieve the purpose of applying RBA in the road structure layer with higher quality and efficiency, the mechanical properties and application requirements of the cement stabilized macadam structure in practical engineering are combined. The high water absorption and high crushed stone value of RBA in this study selected RBA to replace CBA below $4.75 \mathrm{~mm}$ by mass according to the experimental gradation. In addition, considering the reference values of the plastic index and crushed stone values in Table 1, six replacement rates of $0 \%, 20 \%, 40 \%, 50 \%, 60 \%$, and $80 \%$ were selected in this study, and $60 \%$ and $80 \%$ were selected for research integrity. Cement stabilized macadam unconfined compressive strength was taken as the strength index, and the strength formation mechanism of the cement stabilized RBA and CBA mixture was analyzed comprehensively with the "modified EDTA titration experiment". By this method, the effect of RBA on strength depends on the interpreted potential activity activated in the cement stabilized macadam subbase.

\subsection{Specimen Preparation}

The cement stabilized macadam specimens were prepared under optimum moisture conditions to achieve maximum density. A heavy compaction test (T-0804) was used to get the optimum moisture content and the maximum density of each replacement, which are shown in Table 4. As specification (JTG E51-2009) stipulates, the heavy compaction test needs to choose the range of moisture content (5\% by mass) and apply and change with a constant interval (0.5\%) in each experiment to get the curve related to the moisture content and density. Cement, aggregate, and water were shovel-mixed and compacted into a 150-mm diameter by 150-mm high cylinder in three layers and finally pressed into a molding on the press machine. The experiments used $5 \%$ cement by mass of aggregate. According to the Test Methods of Materials Stabilized with Inorganic Binders for Highway Engineering (JTG E51-2009), the degree of compaction of the cylinder specimens was $96 \%$. 
Table 4. Moisture content and maximum density.

\begin{tabular}{ccccccc}
\hline RBA Replacement Rate (\%) & $\mathbf{0}$ & $\mathbf{2 0}$ & $\mathbf{4 0}$ & $\mathbf{5 0}$ & $\mathbf{6 0}$ & $\mathbf{8 0}$ \\
\hline Maximum density $\left(\mathrm{g} \cdot \mathrm{cm}^{-3}\right)$ & 2.362 & 2.215 & 2.167 & 2.143 & 2.122 & 2.152 \\
Optimum moisture content $(\%)$ & 5.11 & 6.87 & 7.04 & 7.35 & 8.17 & 8.31 \\
\hline
\end{tabular}

The specimens were maintained in standard curing room with a temperature of $20 \pm 2^{\circ} \mathrm{C}$ and a relative humidity of more than $95 \%$.

\subsection{Test Methods}

\subsubsection{Strength Test}

The cement stabilized macadam specimens for unconfined compressive strength test followed the T0805-1994 of specification (JTG E51-2009), with curing ages of 7 days, 28 days, and 90 days.

\subsubsection{Modified EDTA Titration Experiment}

The "modified EDTA titration experiment" used the experimental principle of the EDTA cement titration test (T 0809-2009) in the specification (JTG E51-2009). An EDTA experiment is one method to test the effective cement content at the construction set, which mainly measures the $\mathrm{Ca}^{2+}$ content of samples. Meanwhile, the "modified EDTA titration experiment" changed the condition of specimens and contained them in a curing room for 28 days, also taking $\mathrm{Ca}^{2+}$ as the testing project to mainly measure the degree of the pozzolanic reaction of the admixture in the cement stabilized structure. The same chemical principle and reagents are applied in samples of different proportions and $1000 \mathrm{~g}$ quantity was stipulated and used in the "modified EDTA titration experiment". This method was used to measure the degree of pozzolanic activity from pozzolanic admixture in cement or lime stabilized structure at both the construction and experimental field. The quantity of $\mathrm{Ca}(\mathrm{OH})_{2}$ consumed by RBA in specimens with different percent ages was measured in this study, and RBA is considered as a pozzolanic admixture.

Then, $1000 \mathrm{~g}$ cement stabilized macadam mixture specimens were prepared with the replacement ratio in an optimum water contention mixed with cement and maintained for 28 days without compaction. Afterwards, $0.1 \mathrm{~mol} \cdot \mathrm{m}^{-3}$ EDTA-2Na standard solution (ChemChina, Guangrao, Shandong Province, China), $10 \% \mathrm{NH}_{4} \mathrm{Cl}$ solution (ChemChina, Guangrao, Shandong Province, China), $1.8 \%$ $\mathrm{NaOH}$ solution (ChemChina, Guangrao, Shandong Province, China) with triethanolamine (Haihua Company, Weifang, Shandong Province, China), and calcium red indicator (ChemChina, Guangrao, Shandong Province, China) were also prepared and used according to the EDTA titration test (T 0809) in the specification(JTG E51-2009). In this experiment, the sample was soaked in a $\mathrm{NaOH}$ solution that contained twice the mass volume, which remained stationary after stirring for 5 minutes. The static time must be unified among all specimens in one test, and the specific duration is employed according to when the mixture becomes clear. Then, we took $10 \mathrm{~mL}$ supernatant liquid and $50 \mathrm{~mL} \mathrm{NaOH}$ into a $200 \mathrm{~mL}$ conical flask, mixed it up, and tested the PH value using test strips to make sure that it was between 12.5 and 13. Then, $0.2 \mathrm{~g}$ of calcium red indicator was added into the $200 \mathrm{~mL}$ conical flask, which was titrated with EDTA-2Na standard solution after being mixed up. In the comparison test, $300 \mathrm{~g}$ of RBA specimen was weighed and soaked in the $\mathrm{NaOH}$ solution of $600 \mathrm{~mL}$, which was twice the mass volume. The $\mathrm{PH}$ value of the solution was 13 (the $\mathrm{PH}$ value range of the solution environment after cement hydration was 12-13 [21]). We stirred the solution for 5 minutes, put it in a 250ml conical flask after precipitation for 10 minutes, and added $0.2 \mathrm{~g}$ of Cal-Red as the EDTA experiment.

Given the various features of unconfined compressive strength, the activation condition of RBA mainly with its potential activity in cement stabilized macadam construction is discussed. Combined with the mechanism test results, the role of the potential activity of RBA in the strength formation process in cement stabilized macadam construction and the causes are emphatically analyzed. Many 
scholars have studied $[15,22,23]$ and found that a large amount of $\mathrm{Ca}(\mathrm{OH})_{2}$ was consumed in the process of the potential activity of clay bricks being activated to form strength, but these research studies lackeda specific chemical test as proof. These results prove that RBA can be activated by $\mathrm{Ca}(\mathrm{OH})_{2}$ and produce hydration products. Through physical, mechanical, and chemical means, we obtain the conclusion that RBA has potential activity, and can improve the unconfined strength if blended it in a proper method.

\section{Test Results and Analysis}

\subsection{Unconfined Compressive Strength Test}

The unconfined compressive strength of $7 \mathrm{~d}$ is the only hard and fast rule regarding the design of cement stabilized macadam(JTG/T F20-2015). Specimens were used with curing ages of 7 days, 28 days, and 90 days, respectively, and the values of specimens with replacement amounts of RBA of $0 \%$, $20 \%, 40 \%, 50 \%, 60 \%$, and $80 \%$ are shown in Table 5 .

Table 5. Representative value of unconfined compressive strength.

\begin{tabular}{ccccccc}
\hline RBA Replacement Rate (\%) & $\mathbf{0}$ & $\mathbf{2 0}$ & $\mathbf{4 0}$ & $\mathbf{5 0}$ & $\mathbf{6 0}$ & $\mathbf{8 0}$ \\
\hline 7d UCS (MPa) & 5.37 & 3.88 & 4.22 & 5.46 & 4.22 & 3.77 \\
28d UCS (MPa) & 7.07 & 5.77 & 7.08 & 7.62 & 7.09 & 6.51 \\
90d UCS (MPa) & 8.05 & 8.61 & 8.29 & 9.61 & 8.20 & 9.78 \\
7-28d UCSIV (MPa) & 1.70 & 1.89 & 3.19 & 2.16 & 2.87 & 2.74 \\
7-90d UCSIV (MPa) & 2.68 & 4.73 & 4.07 & 4.15 & 3.98 & 6.01 \\
7-28d UCSIP (\%) & 31.66 & 48.71 & 67.77 & 39.56 & 68.01 & 72.70 \\
7-90d UCSIP (\%) & 49.91 & 121.91 & 96.45 & 76.01 & 94.31 & 159.42 \\
\hline
\end{tabular}

$7 \mathrm{~d}$ UCS, 28d UCS, and 90d UCS represent the mean $7 \mathrm{~d}$ unconfined compressive strength,28d unconfined compressive strength, and 90d unconfined compressive strength, respectively. 7-28d UCSIV(or7-90d UCSIV) represent the difference between $28 \mathrm{~d}$ (or 90d) and 7d of unconfined compressive strength values. 7-28d UCSIP (or7-90d UCSIP) represents anunconfined compressive strength increase percentage of $28 \mathrm{~d}$ (or $90 \mathrm{~d}$ ) compared with $7 \mathrm{~d}$. Unconfined compressive strength of $28 \mathrm{~d}$ and $90 \mathrm{~d}$ are both compared with $7 \mathrm{~d}$ because the value of $7 \mathrm{~d}$ is always used to indicate the practical engineering as the main index for whether the next step can be applied.

Combining Table 5, Figure 6, and Table 1, there are several features can be listed:

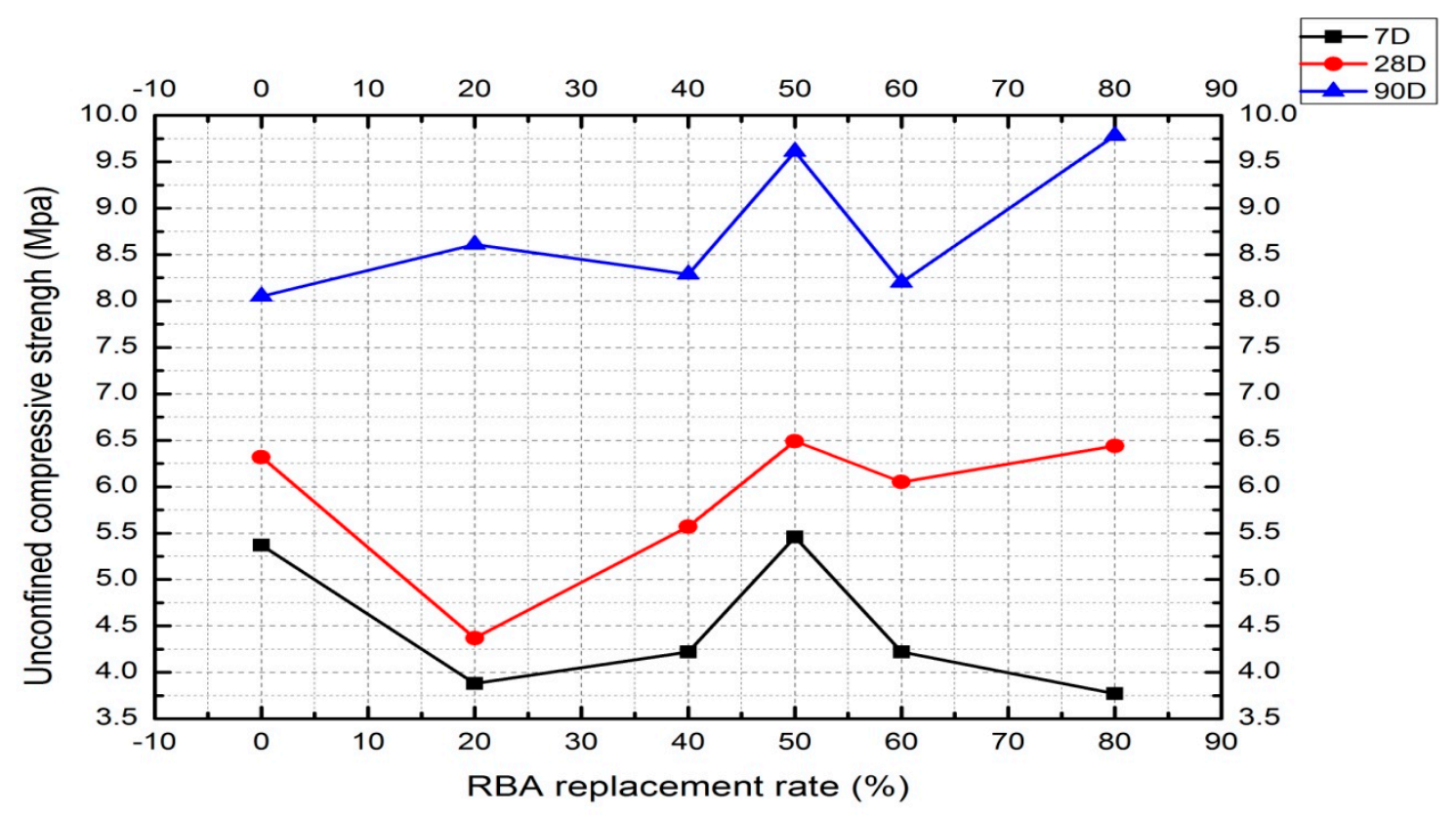

Figure 6. Compressive strength. 
(1) Replacing part of CBA with RBA in cement stabilized macadam fine aggregate will have a great effect on its strength, and the change in the law of strength at various agesis slightly different from the change of RBA content.The strength of $7 \mathrm{~d}$ and $28 \mathrm{~d}$ decreases at first, andthen increases and decreases again with the increasing of RBA content. The $7 \mathrm{~d}$ strength is slightly higher than that of the standard specimen (RBA $0 \%$ ) when the RBA content is $50 \%$, and the strength of other RBA contents is lower than that of the standard specimen. The $28 \mathrm{~d}$ strength of $40 \%, 50 \%$, and $60 \%$ RBA content is close to or slightly larger than the standard specimen, and the strength of other RBA contents is less than the standard specimen. However, the 90d strength of the specimens mixed with RBA is higher than that of the standard specimens.

(2) The property of aggregate has a non-negligible influence on strength at an early stage. Strengths of $7 \mathrm{~d}$ and $28 \mathrm{~d}$ show that $20 \%$ is smaller than $0 \%$ because the pozzolanic reaction is weak; as the replacement ratio increases, the pozzolanic reaction becomes stronger and counteracts the weakening caused by the RBA aggregate, so the strength increases gradually. At the same time, the crushed stone value and the plastic index also increase, exceeding the reference values until the $60 \%$ RBA replacement ratio directly caused either the strength to decrease again or be maintained at a relatively stable level.

(3) Since the increased percentage of strength was composed of the continuous hydration of cement and the activation of the potential activity of RBA, as the curing time increased, the strength of specimens containing RBA increased as well. The strength of the $90 \mathrm{~d}$ kept increasing because the pozzolanic reaction started during the hydration reaction and enough hydration product was formed, leading to the higher strength of the RBA specimens.

(4) According to the various strength characteristics at 7d, 28d, and 90d, the 50\% RBA replacement ratio has the optimal strength, and it can be the recommended as the replacement percentage of RBA in cement stabilized macadam.

\subsection{Modified EDTA titration experiment}

In the comparison test, the solution with Cal-Red was purple at first and turned blue after $0.40 \mathrm{~mL}$ of EDTA-2Na standard solution was consumed. This change (in Figure 7) proved that clay brick contains soluble calcium and can be dissolved in a solution environment after cement hydration. The titration results of specimens prepared in different replace proportions are shown in Table 6.

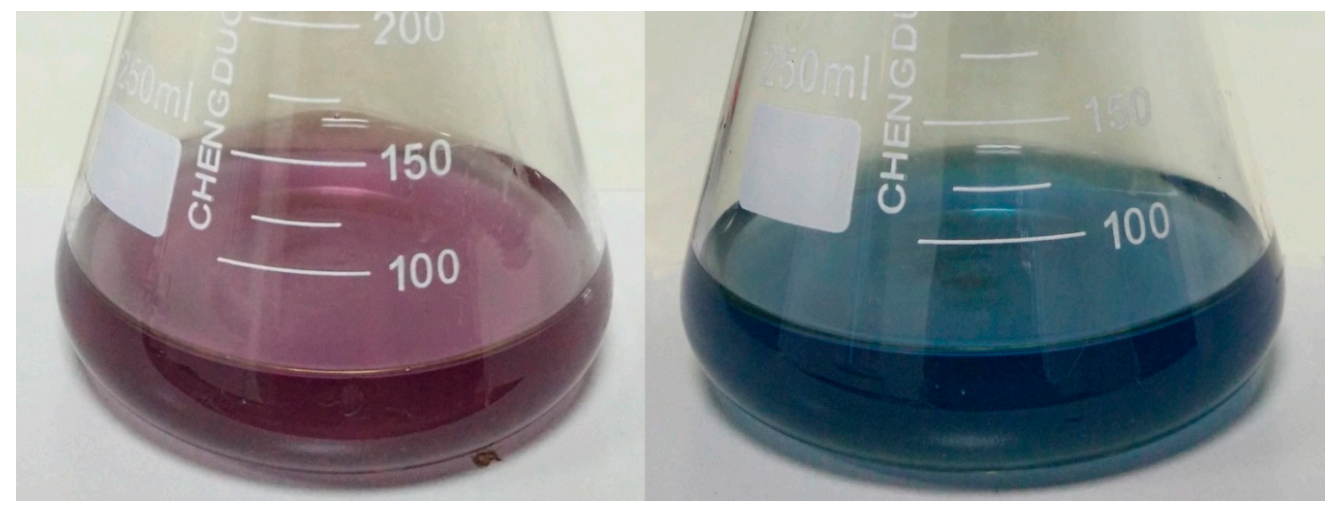

Figure 7. Diagram.

Table 6. EDTA titration value.

\begin{tabular}{ccccccc}
\hline Replacement Rate $(\%)$ & $\mathbf{0}$ & $\mathbf{2 0}$ & $\mathbf{4 0}$ & $\mathbf{5 0}$ & $\mathbf{6 0}$ & $\mathbf{8 0}$ \\
\hline $\begin{array}{c}\text { EDTA-2Na standard solution } \\
\text { consumption } \Delta \mathrm{V}(\mathrm{mL})\end{array}$ & 6.05 & 4.15 & 3.20 & 2.35 & 2.40 & 2.55 \\
\hline
\end{tabular}

Specimens with $50 \%, 60 \%$, and $80 \%$ replacement ratios have the almost same content level of $\mathrm{Ca}^{2+}$, of which $50 \%$ has the lowest content of $\mathrm{Ca}^{2+}$ among them. This indicated that more $\mathrm{Ca}(\mathrm{OH})_{2}$ 
is consumed than other types of specimens and specimens with a 50\% replacement proportion have the largest consumption of $\mathrm{Ca}(\mathrm{OH})_{2}$. The increase of the RBA proportion indicated that more soluble calcium in the ammonium chloride solution makes the content of $\mathrm{Ca}^{2+}$ in the specimens with $80 \%$ RBA larger than that of the $60 \%$ specimens. The standard specimen $(0 \%)$ has the maximum $\Delta \mathrm{V}$ and $50 \%$ has the minimal $\Delta \mathrm{V}$, referring to the corresponding $\mathrm{Ca}(\mathrm{OH})_{2}$ consumption.

\subsection{Mechanism Analysis}

From the results above, it can be seen that the unconfined compressive strength at $7 \mathrm{~d}, 28 \mathrm{~d}$, and 90d have particular variation features as the proportion of RBA increases. The maximum value is obtained at $50 \%$ of the specimen at $7 \mathrm{~d}$. While at $28 \mathrm{~d}$ it is kept in a stable range, after $50 \%$, the proportion increases. At $90 \mathrm{~d}$, the strength increases as the proportion increases, and at $50 \%$, it has the almost same value as that at $80 \%$. It means that the potential activity of RBA activated and offset part of the weakness caused by the weak performances of it, which ultimately affected and enhanced the strength of the cement stabilized macadam layer. Combining with the plastic index and crushed stone value showed in Table 1, 50\% is the most appropriate proportion in this study. Comparing with the reference value at $7 \mathrm{~d}$ stipulated for the first-class highway by specification (JTG/T F20-2015), 3-5 MPa is stipulated, and the strength of the $50 \%$ specimens exceeds the upper limit. The "modified EDTA titration experiment "shows the titration results after 28 days' maintenance; the specimens with $50 \%$ of RBA have the minimum content of $\mathrm{Ca}^{2+}$. Of this proportion, the potential activity of RBA was enormously stimulated and satisfied most of the specifications. When the replacement ratio increases to $80 \%$, the $\mathrm{CaO}$ in clay brick increases because $\mathrm{RBA}$ in $80 \%$ consumes a similar $\mathrm{Ca}^{2+}$ amount of $50 \%$, and the strength results showed that the strength generated by potential activation can offset the strength weakened by the weak performances of the part of RBA and improve the strength level.

It can be proved that the activation of RBA activity is based on the hydration reaction of cement. The potential activation of RBA from the strength makes use of the product of the cement hydration reaction. The consumption of this product makes the activated part of RBA form strength at a rate less than that of the cement hydration reaction. $\mathrm{xCaO} \cdot \mathrm{SiO}_{2} \cdot \mathrm{yH}_{2} \mathrm{O}$ (calcium silicate hydrate, short for $\mathrm{C}-\mathrm{S}-\mathrm{H})$ and $\mathrm{Ca}(\mathrm{OH})_{2}$ are major products of the hydration reaction. After a period of time, a certain amount of $\mathrm{Ca}(\mathrm{OH})_{2}$ is produced. Then, $\mathrm{Ca}(\mathrm{OH})_{2}$ and $\mathrm{SiO}_{2}$ in $\mathrm{RBA}$ react as shown in Equation (1).

$$
\mathrm{Ca}(\mathrm{OH})_{2}+\mathrm{SiO}_{2}+\mathrm{H}_{2} \mathrm{O} \rightarrow \mathrm{xCaO} \cdot \mathrm{SiO}_{3} \cdot \mathrm{yH}_{2} \mathrm{O}
$$

In Equation (1), $\mathrm{Ca}(\mathrm{OH})_{2}$ (form cement hydration), $\mathrm{SiO}_{2}$ (the main substances in clay brick), and $\mathrm{H}_{2} \mathrm{O}$ react and produce $\mathrm{xCaO} \cdot \mathrm{SiO}_{2} \cdot \mathrm{yH}_{2} \mathrm{O}$. This reaction to some extent increases the hydration product $\mathrm{C}-\mathrm{S}-\mathrm{H}$ of cement and increases the amount of the cement that participates in a hydration reaction. When the RBA content reaches a reasonable value, i.e., $50 \%$ in this paper, the $\mathrm{SiO}_{2}$ in clay brick consumes a large amount of the $\mathrm{Ca}(\mathrm{OH})_{2}$ produced by the cement hydration reaction, and produces $\mathrm{xCaO} \cdot \mathrm{SiO}_{3} \cdot \mathrm{yH}_{2} \mathrm{O}$ with a cementitious effect and increases a part of the strength.

For $50 \%$, the increased strength not only offsets the weakened strength due to the weak performances of RBA, but also achieves a higher strength level than the specimen without RBA replacing $\mathrm{CBA}$, and satisfied most of the specifications.

\section{Conclusions}

In order to reuse a large amount of construction waste, clay bricks ought to be used in road engineering, as it reduces the environmental and economic pressure. Unconfined compressive strength of cement stabilized macadam subbase is the main strength index in the structure designing process; combining with SEM scanning, XRD scanning and "modified EDTA titration experiment", we studied the contribution of the potential activity of RBA to the strength of cement stabilized macadam subbase and the activation mechanism of its potential activity. 
1. Component tests of SEM and XRD scanning showed that $\mathrm{SiO}_{2}$ andCaCO${ }_{3}$ exist in clay brick as the dominant ingredient.

2. When construction waste clay brick is mixed into cement stabilized macadam in the form of aggregate below $4.75 \mathrm{~mm}$, there is an optimum content of $50 \%$ under the strength standard with the RBA in performance described in this article, and the unconfined compressive strength of $7 \mathrm{~d}$, $28 \mathrm{~d}$, and $90 \mathrm{~d}$ are 5.46MPa, $7.62 \mathrm{MPa}$, and 9.61MPa respectively, which are greater than the strength of the cement stabilized macadam standard specimen and the values stipulated in specification.

3. The titration results of the "modified EDTA titration test" show that $50 \%$ of specimens have the lowest content of $\mathrm{Ca}^{2+}$, and the potential activity is maximized in this proportion.

4. All the experimental results show that the RBA used in this study has potential activation in cement stabilized structure, and the optimal replace proportion (50\%) of RBA in cement stabilized macadam subbase is proven. In this proportion, RBA replaced CBA and enhanced the unconfined compressive strength; at this time, the potential activity is fully stimulated. Appropriate methods exist to digest construction waste in large quantities and solve the problem of funding for the disposal process. According to this blending method and proportion, it can be widely applied in the road structure subbase, which can solve the problems of environmental governance and economic problems.

Author Contributions: Conceptualization, C.L. and Y.W.; methodology, Y.W. and Y.G.; validation, C.L.; formal analysis, Y.L.; investigation, Y.W. and Y.G.; writing—original draft preparation, C.L.; writing—review and editing, Y.W. and G.T.; project administration, C.L.; funding acquisition, C.L. and W.S.

Funding: This research was funded by the Science Technology Development Program of Jilin Province grant number 2018ZDGC-9-1 and the National Natural Science Foundation of China grant number 51478203.

Acknowledgments: The authors would like to thank the anonymous reviewers for their constructive suggestions and comments to improve the quality of the paper. In addition, thanks to the Second Highway Bureau of China Communications Construction incorporated company for the supply of raw materials.

Conflicts of Interest: The authors declare no conflict of interest.

\section{References}

1. Ten Global Trends for 2019. Available online: https://www.atkearney.com/web/global-business-policycouncil/article/?/a/year-ahead-predi (accessed on 12 March 2019).

2. Wang, J.Y. Study on the Comprehensive Utilization of Construction Waste in the Process of Urbanization. Wall Mater. Innov. Energy Sav. Build. 2013, 6, 38-41. (In Chinese)

3. Marzouk, M.; Azab, S. Environmental and economic impact assessment of construction and demolition waste disposal using system dynamics. Resour. Conserv. Recycl. 2014, 82, 41-49. [CrossRef]

4. Song, Y.Z.; He, Z.Q.; Shen, B.W. The application of the technology of dregs and granule filling in the subgrade construction of expressway. Highway 2016, 61, 86-89. (In Chinese)

5. Yang, J.P.; Zhang, M.X.; Li, X.B. Application of Recycled Construction Materials in Special Foundation Treatment of Road Engineering. Road Mach. Constr. Mech. 2016, 33, 95-98. (In Chinese)

6. Li, X.J. Study on the Pavement Structure of Light Traffic Highway in which Construction Waste Used as the Basic Course. Material. Master's Thesis, Southwest University of Science and Technology, Mianyang, China, 2016. (In Chinese).

7. Guo, Y.L. Comprehensive comparative analysis of construction waste treatment at home and abroad. Manag. Res. Sci. Technol. Management and Research on Scientific \& Technological Achievements. 2015, 11, 28-30. (In Chinese)

8. Li, Y.; Xu, S.H. Study on the Current Situation of Construction Waste. Constr. Technol. 2007, 36, 480-484. (In Chinese)

9. Li, N.; Li, X.Z. Learn from the experience in recycling of construction waste in developed countries. Renew. Resour. Circ. Econ. 2009, 6, 41-44. (In Chinese)

10. Wang, L.C. Study on Legal Regulation of Construction Waste. Master's Thesis, Huaqiao University, Quanzhou, China, 2017. 
11. Xue, C.Z.; Shen, A.Q.; Guo, Y.C.; Wan, C.G.; Zhang, J. Impact of Construction Waste Composite Powder Material on Concrete Anti-frost Performance. Mater. Rev. 2014, 30, 121-125. (In Chinese)

12. Zhu, P.; Mao, X.Q.; Qu, W.J.; Li, Z.Y.; Ma, Z.G. Investigation of using recycled powder from waste of clay bricks and cement solids in reactive powder concrete. Constr. Build. Mater. 2016, 113, 246-254. (In Chinese) [CrossRef]

13. Cheng, H.L. Experimental study on recycled concrete of fly ash and waste clay brick. Concr. Cem. Prod. 2005, 5, 48-50. (In Chinese)

14. Khalaf; Fouad, M. Using Crushed Clay Brick as Coarse Aggregate in Concrete. J. Mater. Civ. Eng. 2006, 18, 518-526. [CrossRef]

15. Fořtová, K.; Pavluring, T. The Performances of Fine Recycled Aggregate Concrete Containing Recycled Bricks from Construction and Demolition Waste. Key Eng. Mater. 2018, 760, 193-198. [CrossRef]

16. Xiao, Z.; Ling, T.C.; Kou, S.C.; Wang, Q.; Poon, C.S. Use of wastes derived from earthquakes for the production of concrete masonry partition wall blocks. Waste Manag. 2011, 31, 1859-1866. [CrossRef] [PubMed]

17. Hu, L.Q.; Sha, A.M. Performance Test of Cement Stabilized Crushed Clay Brick for Road Base Material. China J. Highw. Transp. 2012, 3, 73-79. (In Chinese)

18. Turanli, L.; Bektas, F.; Monteiro, P.J.M. Use of ground clay brick as a pozzolanic material to reduce the alkali-silica reaction. Cem. Concr. Res. 2003, 33, 1539-1542. [CrossRef]

19. Peng, C.J. Study on Performances of Recycled Coarse Aggregate Asphalt Concrete. Master's Thesis, South China University of Technology, Guangzhou, China, 2017. (In Chinese).

20. Li, L.H.; Zhang, N.L. Road Building Materials, 1st ed.; Tongji University Press: Shanghai, China, 1999; pp. 18-23. (In Chinese)

21. Hu, S.G. Advanced Cement-based Composites; Science Publishing \& Media Ltd.: Beijing, China, 2017; pp. 81-85.

22. $\mathrm{Pu}, \mathrm{X} . \mathrm{C} . ;$ Wang, Y.W. High-performance active mineral admixtures and concrete. Concrete 2002, 2, 3-7. (In Chinese)

23. Pu, X.C.; Wang, Y.W. High-performance active mineral admixtures and concrete (continued). Concrete 2002, 3, 21-24. (In Chinese)

(C) 2019 by the authors. Licensee MDPI, Basel, Switzerland. This article is an open access article distributed under the terms and conditions of the Creative Commons Attribution (CC BY) license (http://creativecommons.org/licenses/by/4.0/). 